Supplement of Hydrol. Earth Syst. Sci., 25, 3455-3469, 2021

https://doi.org/10.5194/hess-25-3455-2021-supplement

(C) Author(s) 2021. CC BY 4.0 License.

(c) (i)

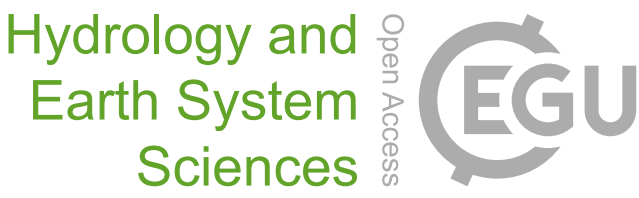

Supplement of

\title{
Attribution of growing season evapotranspiration variability considering snowmelt and vegetation changes in the arid alpine basins
}

Tingting Ning et al.

Correspondence to: Qi Feng (qifeng@1zb.ac.cn)

The copyright of individual parts of the supplement might differ from the article licence. 

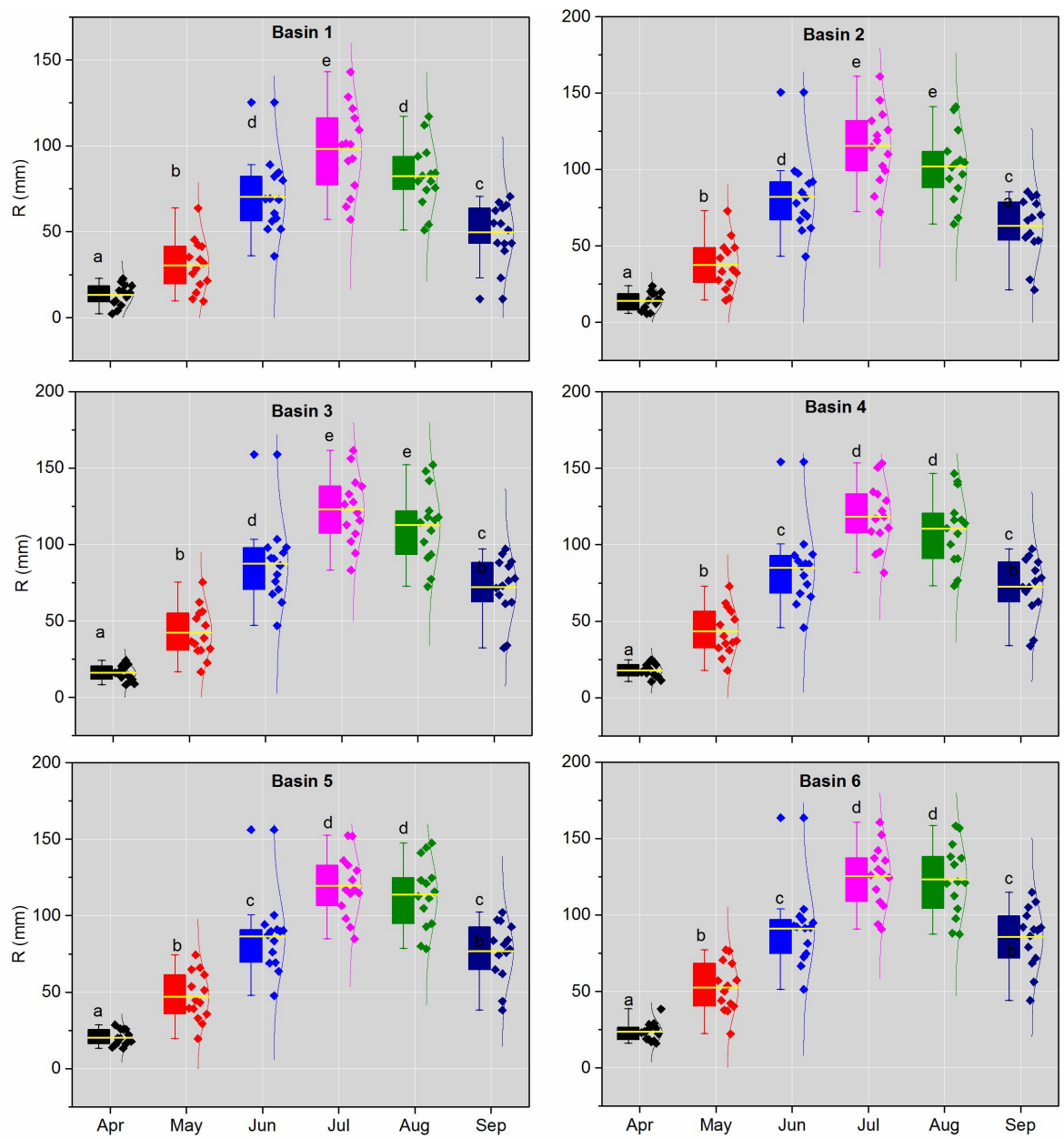

Figure S1 The variation of monthly rain for each basin during 2001-2014. A distribution curve is shown to the right side of each box plot, and the data points are represented by diamonds. Different letters indicate significant differences at $p<0.05$. 

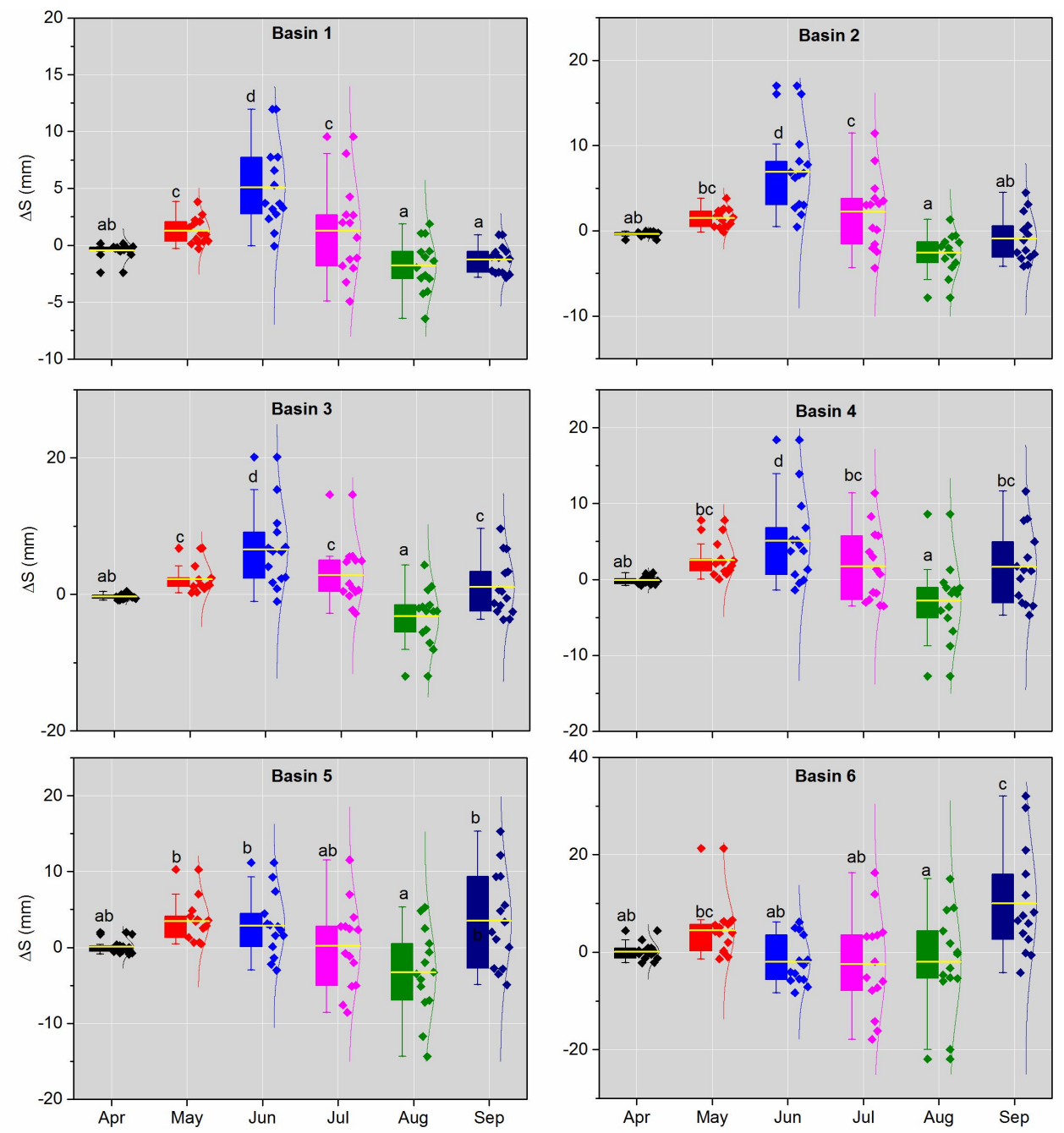

Figure S2 The variation of monthly water storage change for each basin during 2001-2014. A distribution curve is shown to the right side of each box plot, and the data points are represented by diamonds. Different letters indicate significant differences at $\mathrm{p}<0.05$. 

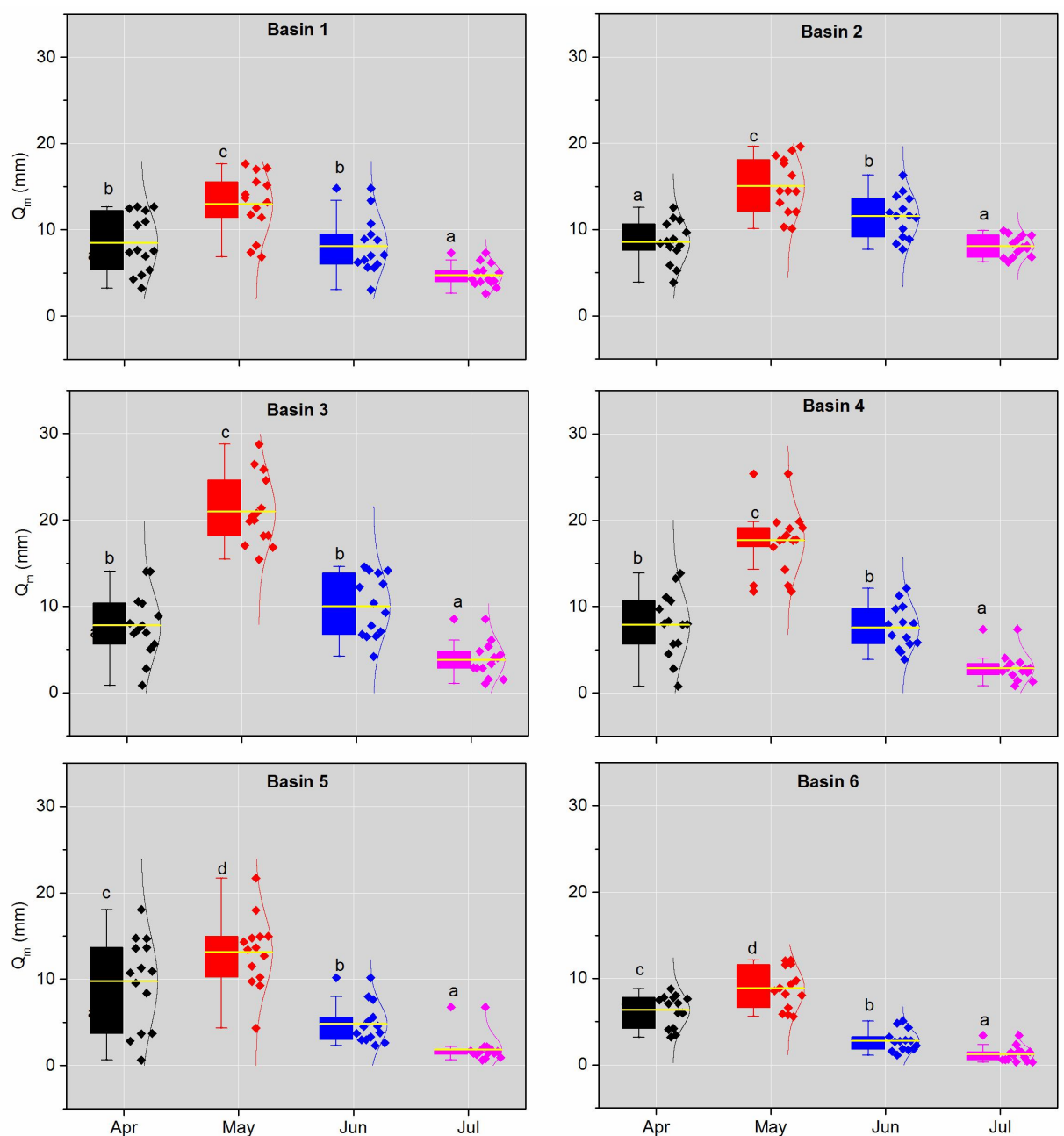

Figure S3 The variation of monthly snowmelt runoff for each basin during 2001-2014. A distribution curve is shown to the right side of each box plot, and the data points are represented by diamonds. Different letters indicate significant differences at $\mathrm{p}<0.05$. 

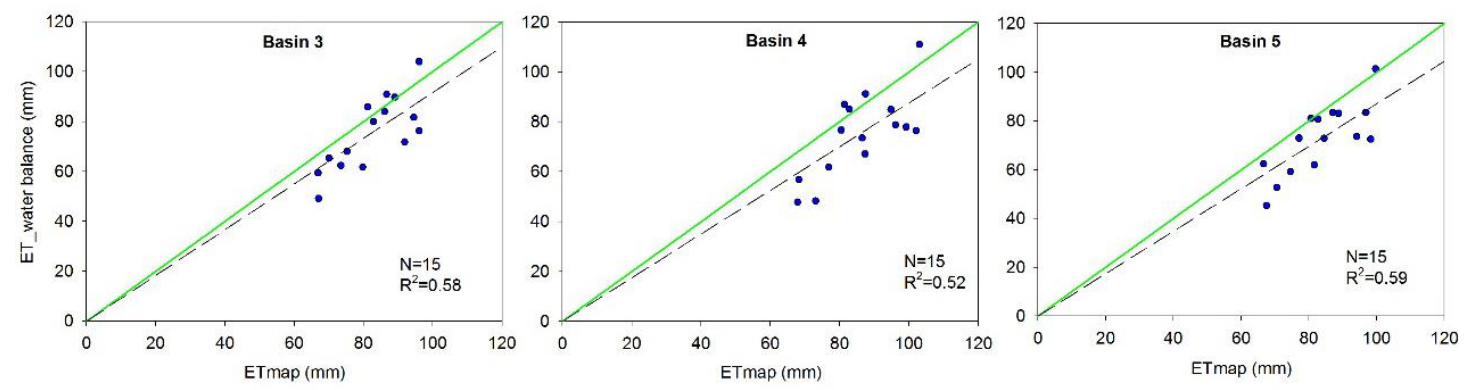

Figure S4. Comparison of monthly ET derived from water balance equation and ETmap during 2012-2014. 